\title{
Agonistic interactions between resident and immigrant sympatric water shrews: Neomys fodiens and $N$. anomalus
}

\author{
Natalia L. KRUSHINSKA, Leszek RYCHLIK* and Zdzisław PUCEK
}

Krushinska N. L., Rychlik L. and Pucek Z. 1994. Agonistic interactions between resident and immigrant sympatric water shrews: Neomys fodiens and $N$. anomalus. Acta theriol. 39: 227-247.

Behavioral mechanisms which control resident-immigrant relations in wild populations of Neomys fodiens (Pennant, 1771) and $N$. anomalus Cabrera, 1907 were studied by quantitative analysis of agonistic interactions between animals inhabiting the enclosure for at least 1 week ('residents') and animals newly introduced ('immigrants'). Tested animals ( $46 \mathrm{~N}$. fodiens and $24 \mathrm{~N}$. anomalus) were observed in one- and two-species groups or pairs in enclosures of $275 \times 135$ or $135 \times 135 \mathrm{~cm}$ built in a laboratory room. During 214 hours of direct observation, social behaviour and patterns of hiding place usage were registered. Individual occupation of the nest boxes, a great number of conflicts among fodiens-'residents', and a large number of conflicts between fodiens-'immigrants' and 'residents' suggest that strong territorial competition in breeding females and strong competition for females in adult males occur between residents and immigrants of the wild $N$. fodiens-populations. Group occupation of the nest boxes, a very low degree of aggressiveness among anomalus-'residents' and the tolerant interactions between anomalus-'immigrants' and -'residents' suggest that, in wild populations, $N$. anomalus are gregarious and inhabit given areas in groups. The low number of interspecific conflicts between 'residents' suggests that in the two-species stabilized groups, behavioral mechanisms exist, which allow $N$. anomalus to avoid conflicts with the more aggressive $N$. fodiens. Since the number of conflicts between fodiens-'residents' and anomalus-'immigrants' is much greater than between 'residents' of the two species, it seems that these mechanisms are active learning rather than simple habituation. The decrease in the number of interspecific conflicts within 1-3 days suggests high efficiency of these mechanisms.

N. K. Koltzov Institute of Developmental Biology, Russian Acad. Sci., 117334 Moscow, Russia (NLK); Mammal Research Institute, Polish Acad. Sci., 17-230 Białowieża, Poland (LR, ZP)

Key-words: Neomys fodiens, $N$. anomalus, agonistic and social behaviour, intra- and interspecific competition, migration

\section{Introduction}

As with many small mammals, there are individuals within shrew populations which either do not have, or abandon, their regular home ranges, and move around

* to whom reprint requests should be sent 
or migrate (Pitt 1945, Shillito 1963a, b, Hawes 1977, Churchfield 1984, 1990, Tegelström and Hansson 1987, Shchipanov and Oleinichenko 1992b). Mammal dispersal is driven by intrinsic (e.g. reproduction strategy) and extrinsic (e.g. social interactions and habitat influences) factors (Stenseth and Lidicker 1992), as well as by the innate inclination to migrate by so-called 'presaturation dispersers' [(Howard 1960, Lidicker 1962, 1975) quoted in Krohne and Burgin 1987]. Migrants inevitably enter areas occupied by conspecifics or individuals of other closely related species.

In small mammal communities, there is strong competition for habitat resources between species which are closely related. Territorial interactions between residents and immigrants of these species are significant because they have a direct influence on the spatial isolation of particular species, viz this isolation diminishes the interspecific competition. In small rodents, interspecific reactions between hosts of a given territory and intruders are related to many behavioural and physiological characteristics of the animals, such as: belonging to a dominating or submissive species (Novak and Getz 1969, Shilov 1977), communication system (Dempster et al. 1992), patterns of parental behaviour (Getz et al. 1992), if given species are sympatric vs allopatric, and also if they are ecological "specialists" vs "generalists" (Dempster and Perrin 1990); as well as prior knowledge about the area where interspecific encounters occur (Wolff et al. 1983, Smirin and Shilov 1989), the size of animals (Blaustein and Risser 1976, Frye 1983, Fox and Kirkland 1992), their gender, age and reproductive status (Dempster and Perrin 1990, Dempster et al. 1992). Our knowledge of these problems in shrews is very limited.

Behavioural interactions between residents and immigrants in shrews have been investigated mainly in laboratory experiments, and very few quantitative studies have been undertaken. The character of these behavioural interactions is diverse. In shrews, which display some territorial behaviour (Sorex araneus, Neomys fodiens, Blarina brevicauda), it has been found that residents usually attack conspecific immigrants and drive them out of their territory (Crowcroft 1957, Bunn 1966, Croin Michielsen 1991), Moreover, residents of Blarina brevicauda kill intruders of the same species (Martin 1981b). However, in other studies (Croin Michielsen 1966, Moraleva 1989) it was found that the resident or adult shrew did not always win. For example, juveniles (sexually immature animals in their first calendar year) of $S$. araneus dominate adults (sexually mature, overwintered animals) when tested in pairs in a neutral area under laboratory conditions. In the wild they displace the older adults, especially males, to poorer places and occupy their home ranges (Moraleva 1989). In conclusion, Moraleva presents the hypothesis that high mortality of overwintered adult $S$. araneus results, at least partly, from the inability to maintain their own territory in competition with the young dispersing animals. Thus, it is obvious that the physiological condition of a shrew competitor for territory is important in the struggle between a territory host and an intruder. 
Two species of European water shrew: Neomys fodiens (Pennant, 1771) and N. anomalus Cabrera, 1907 inhabiting the Białowieża Primeval Forest are an excellent model for the study of competitive territorial interactions between sympatric and syntopic species. The intraspecific social structures of these species differ significantly (Krushinska and Pucek 1989, Krushinska and Rychlik 1993). In mixed groups of $N$. fodiens and $N$. anomalus, inhabiting enclosures, the numbers of intra- and interspecific conflicts decrease with time (Krushinska and Rychlik 1993). Apart from mutual habituation to their co-habitation, there are undoubtedly other behavioural mechanisms which allow $N$. anomalus to avoid the aggression of $N$. fodiens. Therefore, it is interesting to find out, for example, how much time a $N$. anomalus-individual, introduced to a mixed group, needs to learn to avoid the aggression of $N$. fodiens. Do $N$. anomalus form closed or open social groups? Can new individuals enter $N$. anomalus-groups without difficulty? Answers to these questions may help to explain the natural mechanisms of water shrew migration, patterns of space utilization and niche partitioning between these two species.

The purpose of this study was to describe agonistic interactions between water shrews of two species co-inhabiting the enclosure for at least 1 week ('residents') and animals newly introduced ('immigrants') with regard to their species, weight, sex, reproductive status and age. In this way, we hope to generate new ideas about behavioral mechanisms which control resident-immigrant relations in wild populations of water shrews.

\section{Subject and methods}

Forty six Neomys fodiens (17 adult and 13 juvenile males, 3 ad and 13 jv females) and twenty four $N$. anomalus (9 ad and $7 \mathrm{jv}$ males, 3 ad and $5 \mathrm{jv}$ females) captured in the late summer (Aug.-Sep.) of 1988, early summer (June-July) of 1989 and 1991, and spring (May-June) of 1993 in the Bialowieza Primeval Forest were used. All animals underwent at least a 2-week acclimatization in individual cages $(38 \times 30 \times 16 \mathrm{~cm})$. They were then weighed and marked by fur-clipping and/or decolorization with human hair-dye ("Eclair Clair", product of L'OREAL, Paris, France). The marking lasted up to 2 months, and allowed the animals to be distinguished in red light.

The marked animals were introduced to large $(272 \times 135$ and $195 \times 145 \mathrm{~cm})$ or small $(135 \times 135$ $\mathrm{cm}$ ) enclosures built in a laboratory room located in a basement. The small enclosures were formed by partitioning the large ones into halves. The floor was covered with a 5 -cm-layer of sand. A small amount of moss for nest-building was put on the sand and changed every 2-3 weeks. Upturned earthenware flower-pots were provided as nest boxes (exceeding in number the number of animals kept), along with feeding trays, and 1 or 2 water basins $(80 \times 25 \times 15 \mathrm{~cm}$; Fig. 1) within the enclosure. Meat, milk and water were given ad libitum according to Michalak's standard (1987), and the shrews could also prey on live frogs and fish which were put into the enclosures or water basins from time to time.

The sex and age of animals were determined prior to experiments according to external features and proved after experiments by dissection. Sexually active and all overwintered shrews were designated as adults. Immature and sexually inactive shrews in their first calendar year were designated as juveniles. 


\section{Procedure}

Experiment 1: Introduction of a single 'immigrant' to mixed 'resident' groups of $N$. fodiens and $N$. anomalus

Three mixed species groups of 'residents' were formed as well as 'immigrants' were chosen from among available animals acclimatized in individual cages (Table 1). 'Residents' were introduced to the larger enclosures simultaneously. At least 2 weeks after the creation of a mixed group of 'residents' (i.e. after the stabilization of social relations between 'residents') 'immigrants' were introduced successively, one at a time. The 'immigrant' was placed in the middle of the enclosure during evening

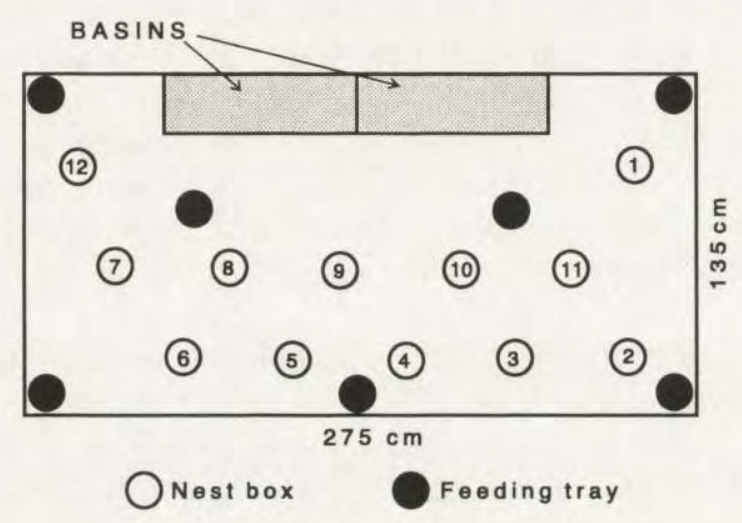

Fig. 1. Design of the enclosure. (In 1991 the enclosure was of size $195 \times 145 \mathrm{~cm}$, and was provided with 5 feeding trays, 10 nest boxes and 1 water basin).

Table 1. The composition of 'resident' groups and the list of 'immigrants' used in experiments. In Exp. 1 'residents' formed the mixed groups in large enclosures, in Exp. 2 'residents' were kept individually in small enclosures. ${ }^{*}$ - the same animals were used as 'residents' and 'immigrants' in different trials.

\begin{tabular}{|c|c|c|c|c|}
\hline \multirow{2}{*}{$\begin{array}{l}\text { Number of } \\
\text { experiment }\end{array}$} & \multirow{2}{*}{ Year } & \multirow{2}{*}{$\begin{array}{l}\text { 'Residents' } \\
\text { composition }\end{array}$} & \multicolumn{2}{|c|}{ 'Immigrants' tested individually } \\
\hline & & & N. fodiens (F) & $N$. anomalus (A) \\
\hline \multirow[t]{3}{*}{1} & 1988 & $\begin{aligned} 6 \mathrm{~F}: & 3 \text { jv males, } \\
& 1 \mathrm{ad}+2 \mathrm{jv} \text { females } \\
5 \mathrm{~A}: & 1 \mathrm{ad}+2 \text { jv males, } \\
& 2 \text { jv females }\end{aligned}$ & $1 \mathrm{ad}+1$ jv males & $\begin{array}{l}1 \text { jv male, } \\
1 \text { ad }+1 \text { jv females }\end{array}$ \\
\hline & 1989 & $\begin{array}{l}5 \mathrm{~F}: 3 \text { ad males, } \\
2 \text { jv females } \\
5 \mathrm{~A}: 3 \text { ad }+2 \text { jv males }\end{array}$ & $\begin{array}{l}2 \text { ad males, } \\
2 \text { ad }+1 \text { jv females }\end{array}$ & $\begin{array}{l}1 \text { jv male, } \\
1 \text { jv female }\end{array}$ \\
\hline & 1991 & $\begin{array}{r}\text { 4F: } 2 \text { ad males, } \\
2 \text { jv females } \\
4 \mathrm{~A}: 3 \text { ad males, } \\
1 \text { ad female }\end{array}$ & $\begin{array}{l}2 \text { ad }+3 \text { jv males, } \\
3 \text { jv females }\end{array}$ & $\begin{array}{l}2 \text { ad }+1 \text { jv males, } \\
1 \text { ad }+1 \text { jv females }\end{array}$ \\
\hline 2 & 1993 & $\begin{array}{c}5 \mathrm{~F}^{*}: 3 \mathrm{ad}+1 \text { jv males, } \\
1 \text { jv female }\end{array}$ & $\begin{array}{l}4 \text { ad }+5 \text { jv males, } \\
2 \text { jv females }\end{array}$ & \\
\hline Total: & & $20 \mathrm{~F}+14 \mathrm{~A}$ & $26+5^{*}$ & 10 \\
\hline
\end{tabular}


hours (i.e. during the high activity period of the animals), and left inside for 3 days. During this time social interactions between an 'immigrant' and each 'resident' as well as interactions among all 'residents' were simultaneously observed for a total of $6 \mathrm{hr}$ ( $2 \mathrm{hr}$ on each of 3 successive evenings). On the 4th day the 'immigrant' was removed. Four $N$. fodiens-'immigrants' and $2 \mathrm{~N}$. anomalus-'immigrants' replaced the 'residents' and stayed in the enclosure for a longer time as new 'residents'. In total, $15 \mathrm{~N}$. fodiens-'immigrants' and $10 \mathrm{~N}$. anomalus-'immigrants' were tested in Exp. 1, and total observation time was $150 \mathrm{hr}$.

In Exp. 1 we (1) compared intra- and interspecific aggressiveness between 'residents' and 'immigrants' of both species with aggressiveness among 'residents', (2) examined if 'immigrants' learned to avoid aggression of 'residents' and how much time it took, (3) examined if $N$. anomalus formed closed or open social groups.

Experiment 2: Introduction of a single $N$. fodiens-immigrant' to a single $N$. fodiens-'resident'

In 1993, single $N$. fodiens-'residents' of different sex and age were placed in small enclosures for at least 1 week. After this time, 'immigrants' were introduced in the same way as in Exp. 1. Social interactions between 'resident' and 'immigrant' were always observed for $4 \mathrm{hr}(2 \mathrm{hr}$ on each of 2 successive evenings), and on the 3rd day the 'immigrant' was removed. Five animals were used both as 'immigrants' and 'residents', while 6 animals were used only as 'immigrants'. In total, 16 tests (4 for each combination of age of a 'resident' and of an 'immigrant') were performed. The total observation time was $64 \mathrm{hr}$.

In Exp. 2 we examined (1) if $N$. fodiens residing in the enclosure alone were more territorial and aggressive than $N$. fodiens-'residents' which shared the enclosure with other conspecifics (Exp. 1), (2) if juvenile $N$. fodiens-'immigrants' were able to dominate adult $N$. fodiens-'resident'. Moreover, in Exp. 2 we followed the experimental design of Moraleva's (1989) study making our results comparable to hers.

During 2-hr observation sessions of Exps 1 and 2, social behaviours displayed by all water shrews present in the enclosure were simultaneously recorded manually in the observation protocols. Most animal interactions could be recorded, because usually there were only 1-3 active shrews. Categories of antagonistic behaviour (threatening postures and/or vocalization, pouncing, chasing, and fighting) were distinguished according to Olsen (1969) and Michalak (1988), and categories of neutrally investigative behaviour according to Shipanov et al. (1987). Areas (i.e. in or near the nest box, near the feeding tray, and in the open area of the enclosure) in which these interactions occurred were also noted.'

When 2 or more conflicts with growing intensity of aggressiveness (e.g. threatening, pouncing, and fighting) followed one by one very quickly (within 1-2 sec), it was interpreted as one conflict of the most aggressive character (i.e. fighting). When, during fighting activity, there was a break of over 10 sec, it was interpreted as 2 separate fighting acts.

On successive days observation sessions were performed during the high activity periods of the animals (i.e. between 18.00 and 00.00 ). Natural light during the day and artificial red light during the night were used for observations. The total duration of observations was $214 \mathrm{hr}$.

The distribution of water shrews in nest boxes was recorded both during observation sessions and by daily checks of their occupation of all the nest boxes during morning hours (i.e. in a low activity period).

\section{Conflict initiating}

We assumed that an animal which initiated conflict was:

(1) in pouncing - an animal which pounced on the other animal,

(2) in fighting

- an animal which attacked first, when it won the fight,

- an initiation score was given to both animals, when the attacked animal won the fight or if 2 individuals attacked each other simultaneously, 
(3) in chasing - an animal which chased the other animal,

(4) in threatening posture and defensive vocalization

- an animal which threatened and/or emitted peeps towards approaching animal (the most common situation),

- an animal which threatened the other animal when approaching it (rarely),

- when 2 individuals began to threaten each other simultaneously, they were attributed one initiation each (occasional occurrence),

(5) in defensive vocalization in/near nest box - an animal which was inside its nest box or which was running out and emitted peeps towards an approaching intruder.

\section{Conflicts inside nest boxes}

Direct observation of conflicts which occurred inside the earthenware nest boxes was impossible. We assumed 4 situations:

(1) initiation of defensive vocalization in nest box by its occupant - when an occupant shrew emitted peeps towards an approaching intruder,

(2) initiation of 1 fight by an occupant and 1 fight by an intruder - when an intruder entered nest box and some evidence of fighting (aggressive vocalization, scratching the walls of nest box, shakes of the whole nest box), were noticeable, after that, the intruder was displaced and the occupant stayed in the nest box,

(3) initiation of 2 fights by an intruder - when an intruder entered and evidence of fighting (as above) were noticeable, after which, the occupant was displaced,

(4) no conflict initiated - when an intruder entered and there was no evidence of fighting.

Most of these fighting activities could be indeed identified by us because fights usually began (and often finished) at the entrance to the nest box, when the intruder was only partly inside (compare Krushinska and Rychlik 1993, pages 15-16).

\section{Data organization and analysis}

The number of occurrences of conflicts of particular categories between all possible pairs of shrews present in the enclosure were listed and summed for each test (i.e. for $2 \mathrm{hr} \times 3$ successive evenings in Exp. 1, and $2 \mathrm{hr} \times 2$ evenings in Exp. 2). These sums were the basic data (shown in figures as $n$ ) to count how many conflicts were initiated by each animal during $1 \mathrm{hr}$. Then, data were grouped according to species, 'resident'-immigrant' status, sex and age classes and compared statistically. We assumed that numbers of conflicts initiated by animals simultaneously present in the enclosure are independent. Because of low number, conflicts of all categories were usually combined in figures. For statistical analysis ANOVA, Spearman correlation coefficient, and Wilcoxon tests were used (Systat Vers. 2.0 - computer program).

\section{Results}

In mixed groups (Exp. 1) there were many more intraspecific conflicts between 'residents' and 'immigrants' in $N$. fodiens than in $N$. anomalus $(0.0001<p<0.001$, ANOVA; Fig. 2). In all cases, the number of conflicts, both intra- and interspecific among 'residents' were lower than between 'residents' and 'immigrants'. These differences were significant in 3 comparisons: for $\mathrm{FI} \rightarrow \mathrm{FR} / \mathrm{FR} \rightarrow \mathrm{FR} p<0.0001$, for $\mathrm{AI} \rightarrow \mathrm{FR} / \mathrm{AR} \rightarrow \mathrm{FR} p<0.05$, and for $\mathrm{FR} \rightarrow \mathrm{AI} / \mathrm{FR} \rightarrow \mathrm{AR} p<0.0001$, ANOVA (Fig. 2). The number of FR $\rightarrow$ AI-conflicts was the highest for all the conflicts observed in mixed groups. At the same time, there was also a greater individual variation in the 'residents'-immigrants' interactions in $N$. fodiens than in $N$. anomalus. In $N$. fodiens $(n=15)$, total number of intraspecific conflicts initiated by 'immigrants' 
during $6 \mathrm{hr}$ was on average $13.5(\mathrm{SD}=$ 12.1 , range $0-51$ ), and that of initiated by 'residents' with 'immigrants' was 10.0 ( $\mathrm{SD}=5.8$, range $0-19$ ), whereas in $N$. anomalus $(n=7)$, total number of conflicts initiated by 'immigrants' was 2.7 (SD = 3.0 , range $0-8$ ), and that of initiated by 'residents' with 'immigrants' was 1.9 $(\mathrm{SD}=2.6$, range $0-7)$.

The number of conflicts between 'residents' and 'immigrants' was the highest on the 1st day after introduction and quickly decreased, so, on the 3rd day it was always lower than on the 1st day (Fig. 3), except for AR $\rightarrow$ AI-conflicts. The number of intraspecific conflicts initiated depended significantly neither on the weight of the shrew which initiated a conflict (for $\mathrm{F} \rightarrow \mathrm{F}: r_{\mathrm{s}}=0.124, \mathrm{df}=537$, $\mathrm{ns}$; for $\left.\mathrm{A} \rightarrow \mathrm{A}: r_{\mathrm{s}}=-0.027, \mathrm{df}=433, \mathrm{~ns}\right)$ nor on the weight of the shrew which was attacked (for $\mathrm{F} \rightarrow \mathrm{F}: r_{\mathrm{s}}=-0.003, \mathrm{df}=537$, $\mathrm{ns}$; for $\mathrm{A} \rightarrow \mathrm{A}: r_{\mathrm{s}}=-0.019, \mathrm{df}=433, \mathrm{~ns}$; Spearman correlation coefficient). The level of aggressiveness depended on age and, to lesser extent, on the animals' gender, what is shown below.

\section{Intraspecific relations in $\boldsymbol{N}$. fodiens}

During the first hours after introduction to mixed groups (Exp. 1) 'immigrants' displayed exploratory activity which disturbed the stable social behaviour of group members. This resulted in the number of conflicts between 'residents' and 'immigrants' (FR $\rightarrow$ FI and $\mathrm{FI} \rightarrow \mathrm{FR}$ ) being significantly higher than that among 'residents' ( $F R \rightarrow F R$ ) (for $\mathrm{FI} \rightarrow \mathrm{FR} / \mathrm{FR} \rightarrow \mathrm{FR} p<0.0001$, ANOVA; Fig. 2). However, the increased number of conflicts initiated by 'immigrants' was observed only on the 1st day after introduction, and on the 3rd day it was

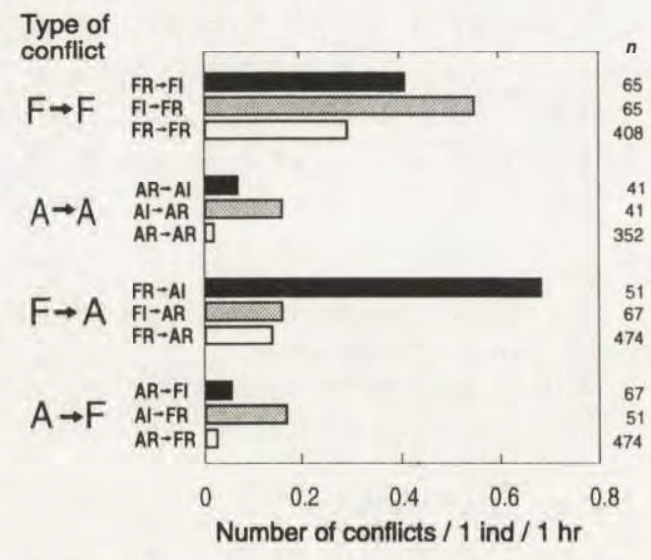

Fig. 2. Aggressiveness of water shrews in the mixed groups (Exp. 1) expressed as the mean number of conflicts initiated by 1 individual during $1 \mathrm{hr}$. Arrows show animals active in conflicts, i.e. FI $\rightarrow$ FR means that $N$. fodiens-'immigrant' attacked $N$. fodiens-'resident', $\mathrm{FR} \rightarrow \mathrm{AI}$ means that $N$. fodiens-'resident' attacked $N$. anomalus-'immigrant', etc. $n$ - number of 6 -hr observations of a particular type of conflicts.

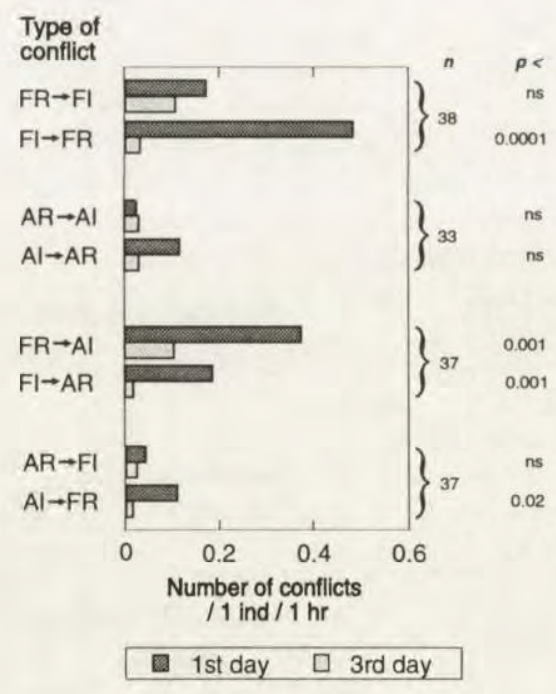

Fig. 3. Aggressiveness between 'residents' and 'immigrants' on the 1st day after introduction (dark bars) in comparison to that on the 3rd day (light bars), observed in the mixed groups (Exp. 1). Number of 6-hr observations of a particular type of conflicts $(n)$ and level of significance $(p)$ are shown. Denotations as in Fig. 2. 
significantly lower $(p<0.0001$, Wilcoxon test; Fig. 3). Intraspecific conflicts in $N$. fodiens were as frequent in the open enclosure as near/in nest boxes. Only 'immigrants' initiated more conflicts near/in nest boxes than in the open enclosure, but this difference was not significant (Wilcoxon test; Fig. 4).

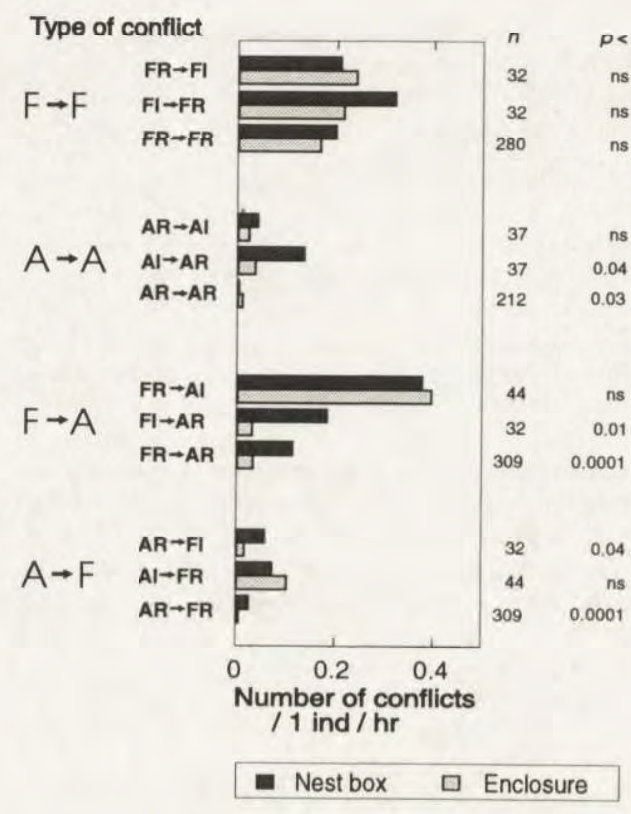

Fig. 4. Aggressiveness of water shrews near/in nest boxes (dark bars) in comparison to that in the open enclosure (light bars), observed in the mixed groups (Exp. 1). Number of 6-hr observations of a particular type of conflicts $(n)$ and statistical significance (p) are shown. Denotations as in Fig. 2.
Type of conflict

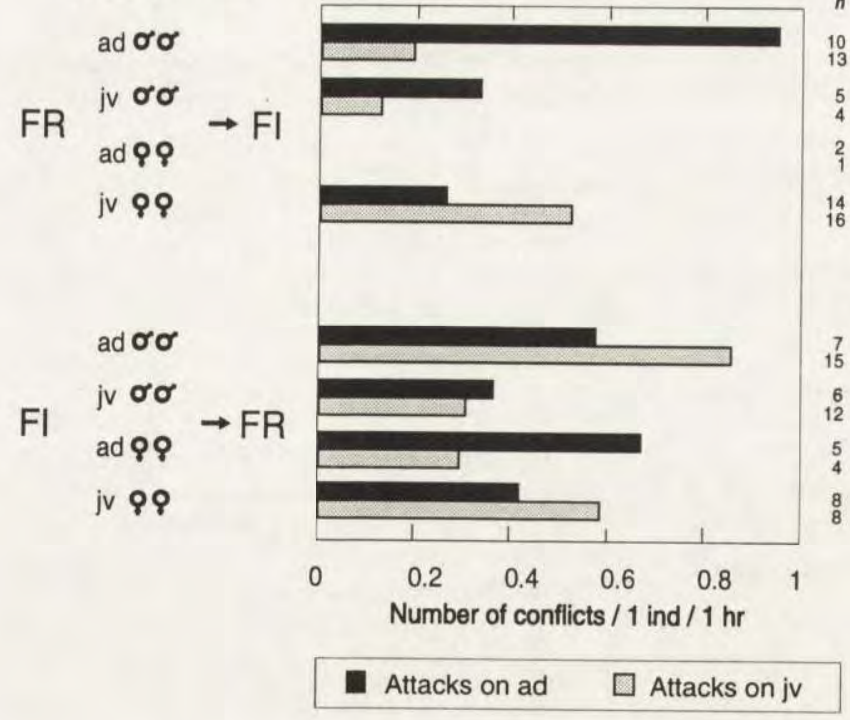

Fig. 5. Aggressiveness between 'residents' and 'immigrants' of Neomys fodiens in regard to their sex and age, observed in the mixed groups (Exp. 1). Denotations as in Fig. 2. 
Among male-'residents': (1) 'Resident' adult males attacked adult 'immigrants' significantly more frequently than young 'immigrants' $(p<0.003$, ANOVA; Fig. 5). (2) The highest degree of intraspecific aggressiveness (but, due to too few observations, this is not confirmed statistically) was displayed by 'resident' adult males towards 'immigrant' adult males ( 1.2 conflicts/ 1 individual $/ 1 \mathrm{hr}$ ).

Among male-'immigrants', which also displayed high aggressiveness towards 'residents', the following relations were ascertained: (1) The number of attacks of 'immigrant' adult males on 'residents' (regardless of sex and age of 'residents') was significantly higher $(p<0.05$, ANOVA) than the number of attacks of 'immigrant' young males on 'residents'. (2) The number of conflicts initiated by 'immigrant' adult males with young 'residents' was significantly higher than those initiated by 'resident' adult males with young 'immigrants' ( $p<0.005$, ANOVA; Fig. 5). (3) Except for conflicts between adult males, there were more FI $\rightarrow$ FR-conflicts than FR $\rightarrow$ FI-ones (Fig. 5).

The 'resident' adult female, in contrast to 'resident' adult males, did not attack 'immigrants' at all in 3 observations (Fig. 5). Interactions between 'resident' males and 'immigrant' females depended on age and the reproductive activity of females, and could vary from strong aggression to courtship behaviour.

For example, the introduction of the FI5 adult female (which probably was in anoestrus at the time) to the 1989 mixed group elicited strong aggression by the one 'resident' adult male, which resulted in frequent and prolonged combats between these 2 shrews near/in nest boxes. On the other hand, after the introduction of the FI7 adult female (which probably was in oestrus), two 'resident' males displayed threatening postures, then courtship behaviour. The FI7 female having shown a preference for one of the males permitted only this male to remain in her nest box. But after 3 days the FI7 female again turned the 'resident' male out of her nest box and attacked him violently. The introduction of the FI6 young female elicited in this 'resident' male only weak investigative reactions and threats in response to her agonistic behaviour.

Thus, in the mixed groups, the highest aggressiveness was displayed between adult males, both 'residents' and 'immigrants'.

In comparison with intraspecific interactions between $N$. fodiens-'immigrants' and 'residents' of the mixed groups (Exp. 1), interactions between 'immigrants' and single 'residents' (Exp. 2) were three times more aggressive (Fig. 6). Since sample numbers were small, results according to the age of animals which initiated conflict were combined. The following statistically significant differences can be seen (Wilcoxon test; Fig. 6): (1) The total (offensive + defensive) number of conflicts initiated by young 'immigrants' was lower than the number of all the other types of conflicts $(p<0.05)$. (2) Adult 'residents' and 'immigrants' initiated significantly more $(p<0.05)$ attacks than defences, whereas in young shrews these differences were not statistically significant. (3) The share of defences in all the conflicts was significantly higher $(p<0.05)$ in FRad $\rightarrow$ FI than in FIad $\rightarrow$ FR.

Moreover, in the tests where 'residents' and 'immigrants' differed in age, the young 'residents' mostly defended themselves against the adult 'immigrants', but did not attack them ( $1.2 \pm 0.9$ defensive vs $0.1 \pm 0.2$ offensive conflicts), whereas the total number of conflicts initiated by young 'immigrants' with adult 'residents' 


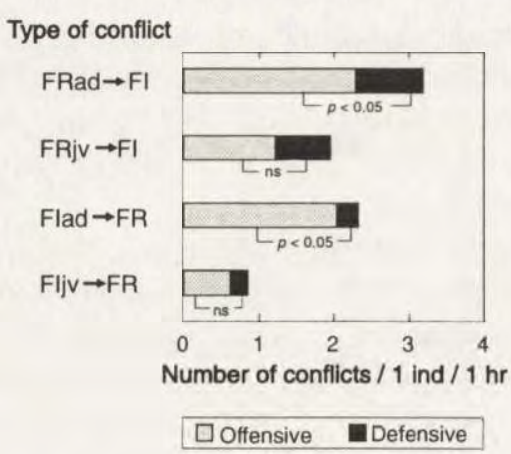

Fig. 6. Mean $(n=8)$ aggressiveness between 'residents' and 'immigrants' of Neomys fodiens in regard to the age of animals initiating a conflict, observed in water shrews tested in pairs (Exp. 2). Denotations as in Fig. 2.

was the lowest observed $(0.8 \pm 0.3)$. Yet, because of low sample numbers $(n=4)$, these relations can not be verified statistically.

\section{Intraspecific relations in $N$. anomalus}

Reactions of $N$. anomalus-'residents' to -'immigrants' in the mixed groups of the two species (Exp. 1) were very tolerant. The number of intraspecific conflicts between 'immigrants' and 'residents' was low and, should the sex and age of the animals not be considered, it did not exceed significantly the number of conflicts among 'residents' (Fig. 2). However, 'immigrant' males (ad and jv) and 'immigrant' adult females attacked 'residents' significantly more frequently than they were attacked by 'residents' $(0.05<p<0.0001$, ANOVA; Fig. 7$)$. The number of conflicts initiated by adult 'immigrants' was also significantly higher than the number of conflicts among 'residents' $(0.004<p<0.0001$, ANOVA). On the other hand, the number of conflicts initiated by 'immigrants' was higher only on the 1st day after introduction, and on the $3 \mathrm{rd}$ day it decreased to the level observed in $\mathrm{AR} \rightarrow \mathrm{AI}$ (Fig. 3 ). However, this change was not statistically significant (Wilcoxon test). Also, 'immigrants' initiated more conflicts near/in nest boxes than in the open enclosure $(p<0.04$, Wilcoxon test; Fig. $4, \mathrm{AI} \rightarrow \mathrm{AR})$. By contrast, conflicts among 'residents' in open enclosure exceeded the number of conflicts near/in nest boxes $(p<0.03$,

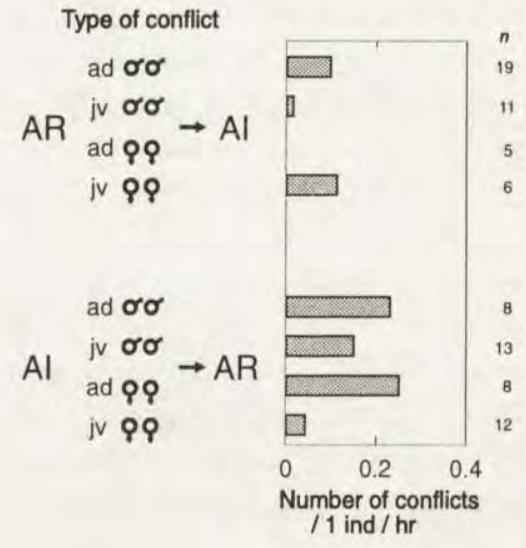

Fig. 7. Aggressiveness between 'residents' and 'immigrants' of Neomys anomalus in regard to the sex and age of animals initiating a conflict, observed in the mixed groups (Exp. 1). Denotations as in Fig. 2. 
Wilcoxon test; Fig. 4, AR $\rightarrow \mathrm{AR}$ ). This resulted in a situation where each $N$. anomalus-'immigrant' occupied a nest box singly during the first 24 hours after introduction to the enclosure, and as late as on the 2nd day it joined $N$. anomalus-'residents' in their common nest box.

\section{Interspecific relations}

The highest number of conflicts observed in the mixed groups (Exp. 1) was that of FR $\rightarrow$ AI (Figs 2 and $8 \mathrm{a}$ ). Especially many of these conflicts were initiated by the $N$. fodiens-'resident' adult female (Fig. 8a), i.e. this 'resident' which did not attack $N$. fodiens-'immigrants' at all (compare Fig. 5). $N$. fodiens-'resident' young females were also relatively very aggressive towards $N$. anomalus-'immigrants' (Fig. 8a).

There were more FR $\rightarrow$ AI-conflicts than $\mathrm{FR} \rightarrow$ AR-conflicts $(p<0.0001$, ANOVA; Fig. 2), what is also true in all combinations of sex and age classes (Fig. 8a). However, the number of FR $\rightarrow$ AI-conflicts decreased quickly, and on the 3rd day it was significantly lower than on the 1st day ( $p<0.001$, Wilcoxon test; Fig. 3 ), and comparable to the number of conflicts observed among 'residents' ( $F R \rightarrow A R$ ).

Similarly, the number of AI $\rightarrow$ FR-conflicts was significantly higher than AR $\rightarrow$ FR-conflicts $(p<0.05$, ANOVA; Fig. 2$)$. This resulted from conflicts initiated

Fig. 8. Interspecific aggressiveness between 'residents' and 'immigrants' compared to that among 'residents', in regard to their sex and age, observed in the mixed groups (Exp. 1). (a) Conflicts initiated by Neomys fodiens. (b) Conflicts initiated by $N$. anomalus. Denotations as in Fig. 2.

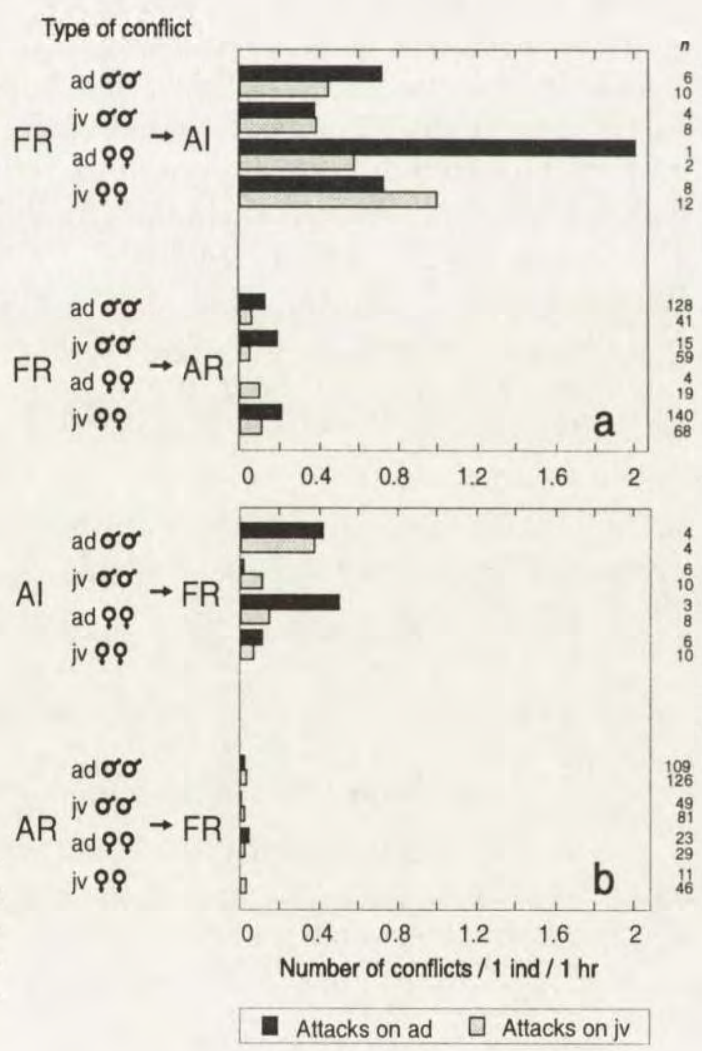


Table 2. Mean ( $n=8$ ) number of agonistic reactions (large fonts) between selected $N$. anomalus -'immigrants' (AI) and $N$. fodiens-'residents' (FR) initiated by 1 individual during $1 \mathrm{hr}$, which were observed during $6 \mathrm{hr}$ of observation in the mixed groups (Exp. 1), as well as levels of statistical significance (Wilcoxon test) of differences indicated (small fonts).

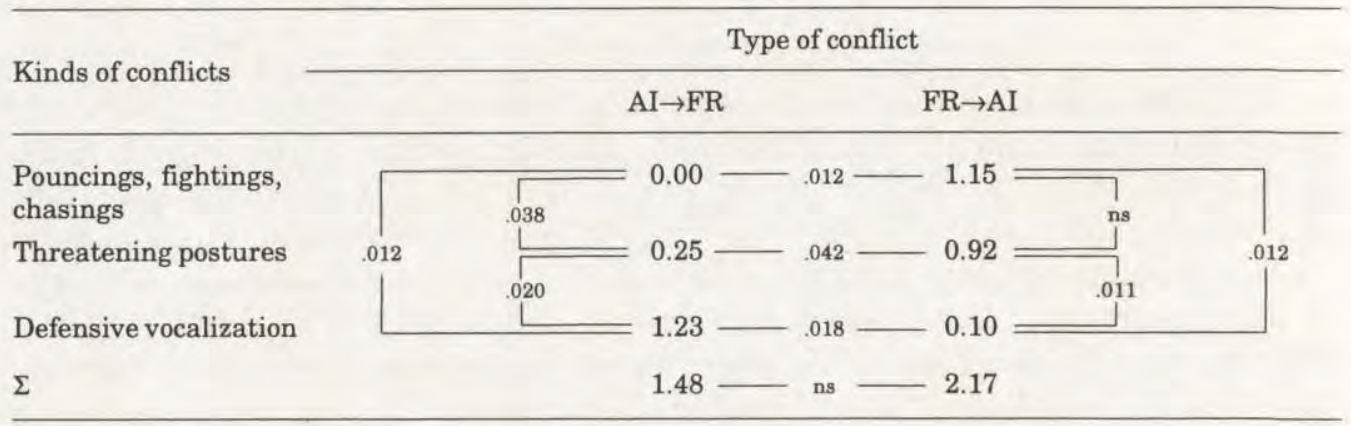

by adult $N$. anomalus-'immigrants' (Fig. 8 b). The numbers of AI $\rightarrow$ FR-conflicts initiated by adult males and females were significantly higher $(p<0.0001$, ANOVA) than that of AR $\rightarrow$ FR-conflicts, whereas the numbers of conflicts initiated by young $N$. anomalus-immigrants' were not. However, after an analysis of these conflicts' features, it appears (Table 2) that interspecific conflicts initiated by $N$. fodiens-'residents' were mostly offensive (pouncings, fightings, chasings), whereas these initiated by $N$. anomalus-'immigrants' were defensive (threatening postures and vocalization). $N$. fodiens-'residents' nearly never displayed the defensive vocalization towards $N$. anomalus-'immigrants', and $N$. anomalus-'immigrants' never attacked $N$. fodiens-'residents'. These differences are significant $(p<0.05$, Wilcoxon test). In addition, although conflicts between $N$. anomalus-'residents' and $N$. fodiens-'residents' occurred much more frequently near/in nest boxes than in the open enclosure ( $p<0.0001$, Wilcoxon test; Fig. 4$), N$. anomalus-'immigrants' were attacked by $N$. fodiens-'residents' to an equal degree near/in nest boxes and in the open enclosure.

Thus, reactions of $N$. fodiens to a strange $N$. anomalus were unequivocally antagonistic and during the first few hours they could assume the forms of drastic persecution.

\section{Discussion}

Intraspecific relations between immigrants and residents

In this paper it has been shown that there is a big difference between $N$. fodiens and $N$. anomalus as to the intraspecific agonistic relations between residents and immigrants. The number of conflicts in $N$. fodiens is far larger than that in $N$. anomalus. The details of these relations in the observed species will be considered below. 


\section{N. fodiens}

The level of intraspecific aggressiveness was mostly determined by whether a 'resident' occupied the enclosure alone or with some other 'residents'. $N$. fodiens residing singly attacked 'immigrants' of their own species (defending probably the whole territory of the enclosure) more fircely than 'residents' being group members. The latter seemingly defended only their nest boxes and the nearest vicinity. This resembles the situation observed by Krushinska and Pucek (1989) who tested groups of 4 individuals of $N$. fodiens in a system of 4 combined cages. At that time each $N$. fodiens defended not only its own nest box, but the whole cage as well. Sorenson (1962), who kept up to 7 Sorex palustris simultaneously in an enclosure $150 \times 300 \mathrm{~cm}$, observed that these shrews defended merely their own nest boxes or food storages. Furthermore, the author concluded that $S$. palustris were not territorial at all. On the other hand, the defence of the whole enclosure observed by us (Exp. 2) confirms the territoriality of $N$. fodiens in wild populations, demonstrated by Cantoni (1993), even more than the animals' behaviour in mixed groups (Exp. 1, and Krushinska and Rychlik 1993).

The number of conflicts between 'immigrants' and 'residents' is considerably greater on the day of introduction than 2 days later, which proves that the processes of establishing the rank of a newcomer among the 'residents' and a potentially new division of the enclosure between the inhabitants are very quick. The high rate of these changes is also underlined by Croin Michelsen (1991) in her experiments on $S$. araneus in the wild. During experimental colonization of islands $S$, araneus set their territories and spare individuals left the islands within $48 \mathrm{hr}$. A year later some newly introduced shrews were chased away from the islands by residents within $24 \mathrm{hr}$. According to Bunn (1966), the intraspecific aggressiveness of $N$. fodiens residents against an intruder decreased with time, and both water shrews could live together in one cage preserving distance between each other due to acoustic communication.

Further differentiation of reactions of 'residents' towards 'immigrants' depended on the sex, age, physiological condition and individual behavioural characteristics of particular individuals. No dependence on the animals' weight was noted. Likewise, Köhler (1986) did not find any relationship between the weight of $N$. fodiens individuals and their intraspecific aggressiveness, and Sorenson (1962) found no relationship between the size of $S$. palustris and the level of their intraspecific aggressiveness. On the grounds of both our experiments presented above we can determine the following sequence from the most to the least aggressive $N$. fodiens : adult males $>$ non-breeding/young females $>$ young males.

In two-species mixed groups, adult 'resident' males of $N$. fodiens attacked adult (especially male) 'immigrants' more frequently than juvenile 'immigrants'. The antagonism of young 'residents' in regard to 'immigrants' was visibly lesser, and of about the same intensity as antagonism displayed to other conspecific 'residents'. Male 'residents' displayed either aggression or sexual interest towards adult 
female 'immigrants', which probably depended on the current phase of the female's oestrous cycle. Therefore, it may be believed that a high level of agonistic reactions in adult males was caused both by their territoriality and competition for females.

Probably, adult breeding females can be even more aggressive than adult males as observations on one parous female of $N$. fodiens suggest (Krushinska and Rychlik 1994). Intraspecific aggressiveness of this female towards introduced males was several times higher than the number of conflicts between male $N$. fodiens-'residents' and -immigrants' in the present study. In $S$. araneus, breeding females seem to dominate adult males and juveniles (Moraleva 1989). The high aggressiveness of breeding females was observed in N. fodiens (Michalak 1983) and some Soricidae (e.g. in B. brevicauda - Platt 1976, C. flavescens - Baxter and Meester 1982, S. isodon - Skarén 1982, S. araneus - Churchfield 1990), as well as in many other mammals, and it is considered as an adaptation against intraand interspecific infanticide.

Literature provides evidence that shrews living as solitary individuals (Blarina brevicauda - Platt 1976, Martin 1981a, b, Crocidura flavescens - Baxter and Meester 1982, N. fodiens - Bunn 1966, Cantoni 1993, S. araneus - Crowcroft 1957, Bunn 1966, Croin Michielsen 1966, 1991, S. coronatus - Cantoni 1993, S. isodon - Skarén 1982) fircely defend their territories against intruders, and their intraspecific aggression usually intensifies in autumn and winter, that is with a drop in food abundance. It was also observed that in S. araneus and $N$. fodiens (Crowcroft 1957, Bunn 1966) individuals residing in cages solitarily usually attacked immigrants first and very violently, that $S$. araneus residents almost always dominated (Croin Michielsen 1991), that in B. brevicauda males dominated over non-breeding females (Martin 1981a), and that B. brevicauda residents, especially males, usually killed introduced alien individuals of the same species (Platt 1976, Martin 1981b). S. palustris (Sorenson 1962) and Suncus murinus (Kawano 1992) are also very aggressive intraspecifically, and their conflicts are often fatal for one of the fighting animals (Sorenson 1962, Tsuji and Naruse 1985 quoted in Kawano 1992). However, there are also data about ambiguous relations between immigrants and residents in e.g. B. brevicauda, kept in one cage in groups (Rood 1958, Platt 1976), which according to Rood (1958) are "playful" species, living peacefully together and in physical contact when sleeping. There were no serious conflicts between residents and female immigrants, and after a few days the newcomers could sleep in one nest box with the residents. However, some of the adult males were very aggressive and it happened that they killed both a female and a male when these were placed in a cage as a pair (Rood 1958). In Martin's examinations (1981b) a young male immigrant of $B$. brevicauda killed an adult female resident (his mother) on the 19th day after introduction.

The observed lack of aggression by an adult $N$. fodiens female residing in a group with regard to conspecific immigrants is difficult to explain. The small number of adult females (only 3 out of 46 ) was investigated in this study. They were very rarely trapped what can suggest that they do not migrate and are strictly 
territorial, at least during breeding season. More adult females should be investigated to understand their social behaviour.

In our experiments we also found significant differences in the behaviour of 'immigrants' with regard to conspecific 'residents'. Again adult 'immigrant' males were most aggressive, and they could either dominate 'residents' or be attacked by 'residents'. However, adult 'immigrants' came into conflict with young 'residents' more often than with adult 'residents'. It was also observed that 'immigrants', to a greater degree than 'residents' (although no statistics confirm this), initiated more intraspecific conflicts near/in nest boxes than in the enclosure. And since 'immigrants', like 'residents', occupied the nest boxes solitarily, one can suggest that it was easier for adult $N$. fodiens-'immigrant' males to win a nest box for themselves through taking it over from immature and physically weaker young $N$. fodiens-'residents'. This hypothesis may be supported by a greater (in comparison to $\mathrm{FR} \rightarrow \mathrm{AR}$ ) number of conflicts near/in the hiding places between $N$. fodiens-'immigrants' and $N$. anomalus-'residents' (the latter being the subordinate species).

Literature provides information about the following patterns of social relations between young shrews leaving nests and adult residents: (1) Being weaker, the young fail in competition with adults and are forced off to suboptimal sites or occupy marginal territories (e.g. N. fodiens - Voesenek and van Bemmel 1984). (2) Young and sexually immature individuals remain in central optimal sites due to the ability to dominate and then force off the adults (e.g. S. araneus - Croin Michielsen 1966, Moraleva 1989). (3) The young remain in central optimal sites (within the home ranges of their mothers) due to the ability to avoid conflicts with adults (e.g. S. vagrans and S. obscurus - Howes 1977).

In our tests on pairs (Exp. 2), young $N$. fodiens-'immigrants' were always dominated by adult 'residents'. So, this excludes the second pattern for this species, i.e. relations which were found in $S$. araneus placed in pairs under laboratory conditions and supported by field observations (Moraleva 1989). We have observed, both in Exps 1 and 2, more amicable behaviour of sexually mature 'residents' towards young 'immigrants' than towards adult 'immigrants'. In the wild, this may be as a result of the young $N$. fodiens leaving nests, with limited risk of confrontation with adults, can remain within the reproducing adults' home ranges until a space is made available after death of older individuals in late summer or autumn, i.e. as in the third pattern. Such a suggestion is already confirmed in some observations: Cantoni (1993) recorded in the wild that $N$. fodiens subadult residents displayed some degree of tolerance towards subadult and juvenile intruders in autumn. According to Köhler (1986), the breaking down of the family unit and dispersion of the young in $N$. fodiens results from an increase in locomotive activity of the young rather than from aggression on the part of the mother. However, this is contradicted by Voesenek and van Bemmel (1984), who found that the young $N$. fodiens are forced off by adults to suboptimal habitats, i.e. as in the first pattern. The furher studies should be carried out to clear this point. 
The difference in intraspecific relations between young 'immigrants' and adult 'residents' of $S$. araneus and $N$. fodiens may result from differences in the time of their sexual maturation. It is well known (Bazan 1955, Spitzenberger 1990) that the current-year $N$. fodiens of the first generation become mature and enter reproduction in the year of birth. In Central Europe, as a rule, S. araneus become sexually mature only after overwintering (Pucek 1960). Therefore, dispersing young $S$. araneus are able to compete effectively with older animals many of which (especially males) may already have lost their physical condition and territories. The dispersing young $N$. fodiens from late litters have to face not only older overwintered animals, but also the physically stronger and sexually mature young from earlier litters over which they are not able to dominate.

In conclusion, if the relations discovered between $N$. fodiens-'residents' and -'immigrants' appear in wild populations, migrations of adult $N$. fodiens at high densities should be very difficult because of frequent and fierce intraspecific conflicts.

\section{N. anomalus}

By contrast with $N$. fodiens, $N$. anomalus-'residents' behaved in a very tolerant manner in regard to conspecific 'immigrants'. A slightly raised level of agonistic interactions was observed in $N$. anomalus-'immigrant' towards -'resident' only on the first day after introduction. That was connected with the 'immigrants" attempts to join common hiding places. The highest number of conflicts was observed between adult 'immigrants' and 'residents'. 'Residents' did not oppose young 'immigrants'. These results, along with earlier estimation of a high tolerance, between $N$. anomalus strangers (Michalak 1982), and between members of socially stable groups, as well as their group utilization of hiding places, a lack of territorial behavoiur, and non-fixed group composition (Krushinska and Pucek 1989, Krushinska and Rychlik 1993) indicate that, in the wild, $N$. anomalus can be a nonterritorial and gregarious species.

In certain respect, social relations in $N$. anomalus are close to those in Cryptotis parva (Conaway 1958), Crocidura russula (Vogel 1969) and C. suaveolens (Shipanov et al. 1987) in captivity. In C. russula, adult couples placed in cages simultaneously manifested signs of antagonism mostly during the first 30 minutes and then always lived in one nest together, even for 3 months (Vogel 1969). Observations of $C$. suaveolens revealed gathering in one hiding place, weakened conflicts at feeding trays and the lack of stable group relations. The process of joining a group of residents by an immigrant in C. suaveolens (under experimental conditions, Shipanov et al. 1987), as in N. anomalus, proceeded without serious conflicts. One may then assume that, in the wild, dispersing youngs could settle without hindrance in areas previously inhabited by a group of residents of no fixed structure. Therefore, in wild populations $N$. anomalus most probably can migrate freely without any risk of being exposed to aggression from their conspecifics and free exchange of group members is possible. 
However, some territorial defence against alien conspecifics was also found in non-solitary shrews. In Cryptotis parva (e.g. Davis and Joeris 1945, Conaway 1958) and several Crocidura species (e.g. Shchipanov 1986, Shipanov et al. 1987, Cantoni and Vogel 1989, Shchipanov and Oleinichenko 1992a, b), which are gregarious and non-territorial during the non-breeding season, the level of intraspecific aggression intensifies, and the animals form couples that defend their territories, during the breeding season. Therefore, with no data on seasonal differences in the spatial structure of a population, it is difficult to predict what the exact intraspecific social relations are between $N$. anomalus-immigrants' and -'resident' in the wild.

\section{Interspecific relations between 'immigrants' and 'residents'}

The interspecific relations between 'immigrants' and 'residents' were characterized by the highest degree of antagonism. $N$. anomalus-immigrants' put into an enclosure inhabited by $N$. fodiens were persecuted during the first hours after introduction in a clearly oriented manner.

Removal of the partitioning which separated one-species $N$. fodiens and $N$. anomalus groups, described in previous studies (Krushinska and Rychlik 1993), may be treated as a simulation of parallel dispersal or migration by several individuals of the same species to a territory occupied by the other species. Also in this case, on the first day after the removal of the partitioning the number of $N$. fodiens attacks on $N$. anomalus was very high. This confirms observations conducted on $N$. anomalus individuals introduced one by one, viz that at least initially they are exposed to frequent attacks by $N$. fodiens.

The highest degree of $N$. fodiens-'resident' aggressiveness towards $N$. anomalus-'immigrants' introduced to the enclosure one by one was not displayed by adult $N$. fodiens males (indicating the highest level of intraspecific antagonism) but, first of all, by females (especially adult), i.e. those $N$. fodiens-'residents' which did not show increased aggression towards conspecific 'immigrants'. Therefore, it may be that individual differences in expressing antagonism by $N$. fodiens towards $N$. anomalus individuals depend on a linear hierarchy in the experimental mixed groups where $N$. anomalus occupy a lower rank, and to a higher degree are subject to attacks on the part of $N$. fodiens females (less aggressive than adult $N$. fodiens males). This confirms the previously observed domination of $N$. fodiens over $N$. anomalus in two-species groups (Krushinska and Pucek 1989, Krushinska and Rychlik 1993).

$N$. anomalus-'immigrants' also more often (in comparison to $N$. anomalus-'residents') initiated conflicts with $N$. fodiens-'residents' during the first hours after introduction. However, the majority of these conflicts were defensive vocal signals emitted from hiding places.

With time the number of conflicts between $N$. anomalus-'immigrants' and $N$. fodiens-'residents' rapidly decreased. This suggests that effective ethological 
mechanisms exist, diminishing the amount of interspecific conflicts shortly after the representatives of these two species meet (that is, immediately after one day). In the interactions observed by us in the enclosure, the following factors could contribute to the decline in the number of interspecific conflicts: (1) a decrease of exploratory activity by 'immigrants', (2) mutual habituation of $N$. fodiens-'residents' and $N$. anomalus-'immigrants' to the presence of the other species, (3) gaining the ability to leave nest boxes asynchronously and having different periods of activity and resting peaks for the two species, (4) maintaining a distance during simultaneous activity of individuals of both species, (5) emission of acoustic signals by active animals, (6) scent marking in close proximity to occupied nest boxes, (7) gathering of all the $N$. anomalus in one nest box. The last strategy of $N$. anomalus-'immigrants' joining $N$. anomalus-'residents' in common hiding places could both decrease the probability of finding $N$. anomalus by $N$. fodiens (Krushinska and Rychlik 1993), and discourage $N$. fodiens-'residents' from attacking all the $N$. anomalus at the same time. We have observed evidence of all the above mentioned mechanisms during our experiments, and some of them will be the subject of further investigations.

When kept in one cage, two $N$. fodiens dominated three $S$. araneus (Köhler 1985). However, in Köhler's study the level of interspecific antagonism was far lower than that of the intraspecific one, and the author's conclusion is that with sufficient food resources and space, the two species may be reared together. Baxter and Meester (1982) describe that very intraspecifically aggressive and solitary $C$. flavescens displayed mutual avoidance (i.e. a low number of conflicts) with Crocidura hirta and Myosorex varius when introduced to their cages. Antagonism of quite large Sorex palustris towards small S. vagrans (Churchfield 1990), and S. palustris towards Peromyscus maniculatus (Sorenson 1962) usually did not lead to direct conflicts, and was limited to the first few hours after the introduction.

Nevertheless, a high degree of interspecific antagonism between residents and immigrants under confined experimental conditions is known for other shrew species. Introduced $S$. araneus were at once severely attacked by $N$. fodiens residing solitarily in cages (Crowcroft 1955), and $S$. minutus immigrants were subject to fierce attacks by dominant $S$. araneus in the first hours after they were placed together in one cage (Crowcroft 1957, Bunn 1966, Churchfield 1990). Blarina brevicauda killed and ate Sorex fumeus (Hamilton 1941).

In the wild, mechanisms of interspecific competition and niche separation in shrews are related to spatial/habitat, trophic, temporal, numerical, morphological (e.g. body size), and behavioural relationships of potential competitors (see review in Kirkland 1991, Fox and Kirkland 1992). As to the behavioural mechanisms, both the direct contacts and agonistic behaviour, as well as strategies to avoid interspecific conflicts, are involved in competitive interactions. For example, it has been proved that direct aggression (pouncing and combats) plays an important role in setting and maintaining the territories of shrews in summer-autumn, as well as in the segregation of ecological niches between $S$. araneus and $S$. minutus 
(Croin Michielsen 1966). These studies provide also evidence that the mutual aggressiveness of sympatric shrew species often observed in captivity (as in our experiments) should not be treated merely as a consequence of stressful experimental conditions, but also as a manifestation of their natural interactions.

However, it seems that mutual avoidance of individuals plays a more important part in reducing of interspecific competition. Usually, representatives of subordinate species quickly leave the vicinity of direct encounters with individuals of dominant species, avoiding any further confrontation (Hawes 1977, Churchfield 1990, Dickman 1991). Therefore, we believe that also in $N$. fodiens and $N$. anomalus, behavioural mechanisms of avoidance of direct encounters (as acoustic and odour communication, temporal differentiation of activity peaks, intra- and interspecific territoriality), together with vertical segregation and differences in microhabitat preferences, plays more important part in diminishing the amount of interspecific conflicts in the wild. These mechanisms enable independent simultaneous colonization of the same areas and coexistence of both water shrew species, as well as migrations of $N$. anomalus across areas occupied by $N$. fodiens.

Acknowledgements: We thank very much Drs S. Churchfield and E. R. Dempster for critical reviewing and constructive comments on early draft of the manuscript, as well as Drs W. Jędrzejewski and W. Bogdanowicz for their help in statistical analysis. We also thank Mrs K. Burnat for help in experiments, Mrs S. Bogdańska and Mrs A. Buszko for their care of animals, and Mr A. Arasim and Mr S. Buszko for their field assistance. Mrs A. Lee Skelly, Mrs S. Gray, and the reviewers kindly corrected our English.

\section{References}

Baxter R. M. and Meester J. 1982. The captive behaviour of the red musk shrew, Crocidura $f$. flavescens (I. Geoffroy, 1827) (Soricidae : Crocidurinae). Mammalia 46: 11-27.

Bazan I. 1955. Untersuchungen über die Veränderlichkeit des Geschlechtsapparates und des Thymus der Wasserspitzmaus (Neomys fodiens fodiens Schreb.). Annls Univ. Mariae Curie-Skłodowska, Sectio C, 9: 213-259.

Blaustein A. R. and Risser A. C., Jr 1976. Interspecific interactions between three sympatric species of kangaroo rats (Dipodomys). Anim. Behav. 24: 381-385.

Bunn D. S. 1966. Fighting and moult in shrews. J. Zool., Lond. 148: 580-582.

Cantoni D. 1993. Social and spatial organization of free-ranging shrews, Sorex coronatus and Neomys fodiens (Insectivora, Mammalia). Anim. Behav. 45: 975-995,

Cantoni D. and Vogel P. 1989. Social organization and mating system of free-ranging, greater white-toothed shrews, Crocidura russula. Anim. Behav. 38: 205-214.

Churchfield S. 1984. An investigation of the population ecology of syntopic shrews inhabiting water-cress beds. J. Zool., Lond. 204: 229-240.

Churchfield S. 1990. The natural history of shrews. Christopher Helm Publ., London: xiv +1-178.

Conaway C. H. 1958. Maintenance, reproduction and growth of the least shrew in captivity. J. Mammal. 39: 507-512.

Croin Michielsen N. 1966. Intraspecific and interspecific competition in the shrews Sorex araneus L. and S. minutus L. Archs néerl. Zool. 17: 73-174.

Croin Michielsen N. 1991. A field experiment on minimum territory size in the common shrew Sorex araneus. Neth. J. Zool. 41: 85-98.

Crowcroft P. 1955. Notes on the behaviour of shrews. Behaviour 8: 63-80.

Crowcroft P. 1957. The life of the shrew. Max Reinhardt, London: 1-166. 
Davis W. B. and Joeris L. 1945. Notes on the life-history of the little short-tailed shrew. J. Mammal. 26: $136-138$.

Dempster E. R., Dempster R. and Perrin M. R. 1992. A comparative study of the behaviour of six taxa of male and female gerbils (Rodentia) in intra- and interspecific encounters. Ethology 91: 25-45.

Dempster E. R. and Perrin M. R. 1990. Interspecific aggression in sympatric Gerbillurus species. Z. Säugetierk. 55: 392-398.

Dickman C. R. 1991. Mechanisms of competition among insectivorous mammals. Oecologia 85: $464-471$.

Fox B. J. and Kirkland G. L., Jr 1992. An assembly rule for functional groups applied to North American soricid communities. J. Mammal. 73: 491-503.

Frye R. J. 1983. Experimental field evidence of interspecific aggression between two species of kangaroo rat (Dipodomys). Oecologia 59: 74-78.

Getz L. L., Larson C. M. and Lindstrom K. A. 1992. Blarina brevicauda as a predator on nestling voles. J. Mammal. 73: 591-596.

Hamilton W. J., Jr 1941. The food of small forest mammals in eastern United States. J. Mammal. 22: 250-263.

Hawes M. L. 1977. Home range, territoriality, and ecological separation in sympatric shrews, Sorex vagrans and Sorex obscurus. J. Mammal. 58: 354-367.

Kawano K. 1992. Aggressive behavior of the domesticated house musk shrew (Suncus murinus) in inter-male, inter-female and heterosexed interactions. J. Ethol. 10: 119-131.

Kirkland G. L., Jr 1991. Competition and coexistence in shrews (Insectivora: Soricidae). [In: The biology of the Soricidae. J. S. Findley and T. L. Yates, eds]. The Museum of Southwestern Biology, University of New Mexico, Albuquerque: 15-22.

Köhler D. 1985. Zum interspezifischen Verhalten von Neomys fodiens und Sorex araneus. Säugetierkdl. Inf. 2: 299-300.

Köhler D. 1986. Zur Ethogenese der Wasserspitzmaus, Neomys fodiens (Insectivora). [In: Verhaltensbiologie, Internationales Symposium, 1983. G. Tembrock, R. Siegmund and M. Nichelmann, eds]. Wissenschaftliche Schriftenreihe der Humboldt-Universität, Berlin: 139-144.

Krohne D. T. and Burgin A. B. 1987. Relative success of residents and immigrants in Peromyscus leucopus. Holarct. Ecol. 10: 196-200.

Krushinska N. L. and Pucek Z. 1989. Ethological study of sympatric species of European water shrews. Acta theriol. 34: 269-285.

Krushinska N. L. and Rychlik L. 1993. Intra- and interspecific antagonistic behaviour in two sympatric species of water shrews: Neomys fodiens and N. anomalus. J. Ethol. 11: 11-21.

Krushinska N. L, and Rychlik L. 1994. Aggressiveness of a Neomys fodiens parous female towards conspecific and $N$. anomalus intruders. Acta theriol. 39: 329-332.

Martin I. G. 1981a. The behavior of the short-tailed shrew, Blarina brevicauda, in captive and simulated natural conditions. Dissertation Abstracts International 41: 2927-B.

Martin I. G. 1981b. Tolerance of conspecifics by short-tailed shrew (Blarina brevicauda) in simulated natural conditions. Am. Midl. Nat. 106: 206-208.

Michalak I. 1982. Reproduction and behaviour of Mediterranean water shrew under laboratory conditions. Säugetierkdl, Mitt. 30: 307-310.

Michalak I. 1983. Reproduction, maternal and social behaviour of the European water shrew under laboratory conditions. Acta theriol. 28: 3-24.

Michalak I. 1987. Keeping and breeding the Eurasian water shrew Neomys fodiens under laboratory conditions. Int. Zoo Yb. 26: 223-228.

Michalak I. 1988. Behaviour of young Neomys fodiens in captivity. Acta theriol. 33: 487-504.

Moraleva N. V. 1989. Intraspecific interactions in the common shrew Sorex araneus in Central Siberia. Ann. zool. Fenn. 26: 425-432.

Novak M. and Getz L. 1969. Aggressive behaviour of meadow voles and pine voles. J. Mammal. 50: $637-639$. 
Olsen R. W. 1969. Agonistic behaviour of the short-tailed shrew (Blarina brevicauda), J. Mammal. 50: 494-500.

Pitt F. 1945. Mass movement of the water shrew Neomys fodiens. Nature, Lond. 156: 247.

Platt W. J. 1976. The social organisation and territoriality of short-tailed shrew (Blarina brevicauda) populations in old-field habitats. Anim. Behav. 24: 305-318.

Pucek Z. 1960. Sexual maturation and variability of the reproductive system in young shrew (Sorex L.) in the first calendar year of life. Acta theriol. 3: 269-296.

Rood J. P. 1958. Habits of the short-tailed shrew in captivity. J. Mammal. 39: 499-507.

Shchipanov N. A. 1986. On ecology of the scilly shrew (Crocidura suaveolens). Zool. Zh. 65: 1051-1060. [In Russian with English summary]

Shchipanov N. A. and Oleinichenko V. Yu. 1992a. On ecology of the white-toothed shrew (Crocidura leucodon). 1. Behaviour, territory use and reproduction of the white-toothed shrew in experiment. A hypothetic scheme of the population density regulation. Zool. Zh. 71: 69-84. [In Russian with English summary]

Shchipanov N. A. and Oleinichenko V. Yu. 1992b. On ecology of the white-toothed shrew (Crocidura leucodon). 2. A field study of spatially-ethological structure of the white-toothed shrew population. Two types settlements. Population numbers regulation in dependence on proportion of the settlements with different spatial structures. Zool. Zh. 71: 110-122. [In Russian with English summary]

Shillito J. F. 1963a. Field observations on the water shrew (Neomys fodiens). Proc, zool. Soc. Lond. 140: $320-322$.

Shillito J. F. 1963b. Observations on the range and movements of a woodland population of the common shrew Sorex araneus L. Proc, zool. Soc. Lond. 140: 533-546.

Shilov I. A. 1977. [The eco-physiological principles of populational relations in animals], Izd. Moscow University, Moscow: 1-261. [In Russian]

Shipanov [sic!] N. A., Shilov A. I. and Bodyak N. D. 1987. Behavior of Crocidura suaveolens observed in confinement. Zool. Zh. 66: 1540-1552. [In Russian with English summary]

Skarén U. 1982. Intraspecific aggression and postnatal development in the shrew Sorex isodon Turov. Ann. zool. Fenn. 19: 87-91.

Smirin Yu. M. and Shilova S. A. 1989. Some features of social behavior of house and wood mice (Mus musculus and Apodemus sylvaticus) in their joint habitation. Zool. Zh. 68: 99-110. [In Russian with English summary]

Sorenson M. W. 1962. Some aspects of water shrew behavior. Am. Midl. Natur. 68: 447-462.

Spitzenberger F. 1990. Neomys fodiens (Pennant, 1771) - Wasserspitzmaus. [In: Handbuch der Säugetiere Europas. Band 3, 1. Insektenfresser-Herrentiere. J. Niethammer and F. Krapp, eds]. Aula-Verlag, Weisbaden: 334-374.

Stenseth N. C. and Lidicker W. Z., eds 1992. Animal dispersal. Small mammals as a model. Chapman \& Hall, London: 1-365.

Tegelström H. and Hansson L. 1987. Evidence of long distance dispersal in the Common shrew (Sorex araneus). Z. Säugetierk. 52: 52-54.

Voesenek L. A. C. J. and van Bemmel A. C. 1984. Intra and interspecific competition in the water shrew in the Netherlands. Acta theriol. 29: 297-301.

Vogel P. 1969. Beobachtungen zum intraspezifischen Verhalten der Hausspitzmaus (Crocidura russula Hermann, 1870), Revue suisse Zool. 76: 1079-1086.

Wolff J. O., Freeberg M. H. and Dueser R. D. 1983. Interspecific territoriality in two sympatric species of Peromyscus (Rodentia: Cricetidae). Behav. Ecol. Sociobiol. 12: 237-242.

Received 13 May 1994, accepted 4 July 1994 